\section{SOI: $1.1 /$ TAS DOI: $10.15863 /$ TAS International Scientific Journal Theoretical \& Applied Science}

p-ISSN: 2308-4944 (print) e-ISSN: 2409-0085 (online)

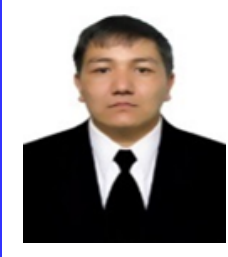

Azizkhon Saidalokhonovich Khojayev

senoir teacher,

The department of "Accounting and audit"

Fergana Politectical Institute imf_azizi83@mail.ru

Year: $2017 \quad$ Issue: 09 Volume: 53

Published: 5.09.2017 http://T-Science.org

SECTION 31. Economic research, finance, innovation, risk management.

\title{
QUESTIONS OF IMPROVING THE USE OF STATISTICAL STUDIES IN COLLECTING INFORMATION IN THE SPHERE OF FRUIT VEGETABLES
}

Abstract: This article covers the field of fruit growing and vegetable growing, the use of statistical research methods in collecting information on it, the issues of further development of the activities of farms, speci fi ed fruit growing and vegetable growing through the improvement of the procedures for obtaining statistical information. The study developed proposals and recommendations for improving the industry using statistical methods.

Key words: statistics, fruit growing-vegetable growing, farms, statistical research, statistical methods, information, collection, processing, respondent, survey.

Language: Russian

Citation: Khojayev AS (2017) QUESTIONS OF IMPROVING THE USE OF STATISTICAL STUDIES IN COLLECTING INFORMATION IN THE SPHERE OF FRUIT VEGETABLES. ISJ Theoretical \& Applied Science, 09 (53): 8-13.

Soi: http://s-o-i.org/1.1/TAS-09-53-2 Doi: crossef https://dx.doi.org/10.15863/TAS.2017.09.53.2

\section{ВОПРОСЫ СОВЕРШЕНСТВОВАНИЯ ИСПОЛЬЗОВАНИЯ СТАТИСТИЧЕСКИХ ИССЛЕДОВАНИЙ ПРИ СБОРЕ ИНФОРМАЦИИ В СФЕРЕ ПЛОДОВОДСТВА-ОВОЩЕВОДСТВА}

Аннотация: В данной статье освещены отрасль плодоводства-овощеводства, вопросы использования методов статистических исследований при сборе информации по ней, вопросы дальнейшего развития деятельности фермерских хозяйств, специлизированных плодоводстве-овощеводстве через совершенствование порядков получения статистических информаций. В исследовании разработаны предложения и рекомендации по совершенствованию отрасли с использованием статистических методов.

Ключевые слова: статистика, плодоводство-овощеводство, фермерские хозяйства, статистическое исследование, статистические способы, информаџия, сбор, обработка, респондент, опрос.

\section{І. Введение}

Статистические исследования, проводимые в целях изучения статистической точки зрения социально-экономических явлений и процессов, в том числе, проблем имеющихся в практической деятельности фермерских хозяйств специализированных в плодоводствеовощеводстве, предусматривают сбор эмпирических данных, применения различных способов и средств их переработки и анализа.

В целях последующей проверки данных полученных в статистической отчетности, определения проблем в деятельности фермерских хозяйств Ферганской области и разработки мер по их устранению осуществлен анкетный опрос в специализированных фермерских хозяйствах.

\section{II. Методология исследования}

Получение статистической информации с использованием способов статистики в данной исследовательской работе, через их обработку приведет к далнейшему развитию отрасли плодоводства-овощевоства, составлению региональных программ а также дальнейшему развитию деятельности фермерских хозйств, специализированных в плодоводстве и овощеводстве.

\section{III. Обзор литературы}

Проблемы развития рынка плодово-овощной и винградной продукции анализирован со стороны таких зарубежных ученых, как Л.В. Агаркова, И.А. Баранов, Н.А. Попов, А.В. 
Афанасьева, М.А. Соломахин, Н.И. Греков $[1,2,3,4,5,6]$.

Вопросы изучения теоретических и практических аспектов организации, управления и повышения эффективности плодовоовощеводства и вингорадарства в нашей Республике на этапе либерализации экономики нашли свое отражение в научных трудах Н.P. Асадулиной, А.Х. Бурхонова, М.М. Мирзаева, Ч. Муродова, Ф. Назаровой, У.П. Умурзокова, Х.С. Хушвактовой, Э.И. Эргашева, У.С. Мухиддиновой, Ш.Т. Эргашевой, Б.Х. Шафкарова, M.

Рахматова $[7,8,9,10,11,12,13,14,15,16]$.

Выше перечисленные научноисследовательские труды внося вклад в аграрноэкономическую науку, служат важнейшей основой научного изучения проблем эффективности с теоретической и практической точки зрения. Но недостаточное уделение внимания вопросам статистического исследования экономической деятельности стала причиной выбора данной темы исследования.

\section{IV. Анализ результатов}

Социально-экономическое развитие данной отрасли, разработка и осуществление необходимых программ, разработка научноэкономически обоснованных предложений по дальнейшему совершенствованию их деятельности на основе изучения состояния экономического развития и перспективы фермерских хозяйств, специализированных в плодоводстве-овощеводстве с помощью опроса, является главной целью проведенных в городах и районах Ферганской области статистических исследований. Данные исследования организованы и проведены на регионах области в следующих этапах:

- определение цели и задач статистического исследования;

- составление текста опроса, урегулирование и умножение;

- $\quad$ проведение статистического опроса;

- обработка статистических данных, анализ, разработка выводов и предложений по результатам исследования.

В статистических исследованиях в качестве участников опроса (респондентов) участвовали 412 фермерских хозяйств, специализированных в плодоводстве-овощеводстве действующих на территории области.

403 человек или 97,8 \% руководителей фермерских хозяйств, участвовавщих в опросе ответили польностью на поставленные автором вопросы анкеты (приложение-6).

Среди респондентов, участвовавщих в опросе по видам продукции основное место занимали фермерские хозяйства специалзированные на плодоводствеягодоводстве - 48\%; бахчевые культуры - 24\%; овощевожство - $20 \%$ и виноградарство - $8 \%$.

По периоду осуществления деятельности фермерские хозяйства осущствляющие деятельность более 5 лет составляют - $49 \%$; от 2 до 5 лет - $24 \%$; меньше 1 года - $16 \%$ и от 1 года до 2 лет $11 \%$.

В доле фермерских хозяйств, специализированных плодоводстве-овощеводстве по площади земельных участков $42 \%$ составляют фермерские хозяйства площадью от 5 до 10 гектаров; от 1,5 до 5 гектаров - $24 \%$, от 10 до 20 гектаров и более 20 гектаров занимают $17 \%$.

В деятельности фермерских хозяйств специализированных плодоводстве-овощеводстве важное место занимают основные средства. Доля респондентов имеющих основные средтва стоимостью до 10 млн. Сум составляет 40 процентов, респонденты не имеющие основные средства - 26\%; респонденты имеющие основные средства стоимостью от 10 до 50 млн. сум - 21\%; респонденты имеющие основные средства стоимостью более 50 млн. сумов - $13 \%$. Обеспеченность основными средствами также оказывает влияние на объем их годовых доходов. Доля фермерских хозяйств, специализированных плодоводстве-овощеводстве и имеющих доходы до 10 млн. сумов составляет - 47\%, от 10 до 25 млн. сумов и от 25 до 50 млн. сумов - $21 \%$, а более 40 млн. сумов - $11 \%$. Это утверждает в свою очередь наше мнение о том, что увеличение стоимости основных средств фермерских хозяйств на 1 млн. сумов возможно увеличение их прибыли на 1,165 млн. сум.

Эффективная деятельность фермерских хозяйств, специализированных плодоводствеовощеводстве занимает важное место в решении проблемы занятости. Основное место занимают фермерские хозяйства (44\%) с количеством работников 3-5 человек, от 5 до 10 человек $26 \%$, до 3 человек - $19 \%$ и более 19 человек $11 \%$. Соотношение работников по уровню средней доходности выглядеть по следующему: работники со средными доходами 300-500 тыс. сум - 44\%, 100-300 тыс. сум - 23\%, более 100 тыс. сум - 22\%, а более 500 тыс. сум $-11 \%$.

При опросе респондентов о проблемах при выращивании плодово-овощной продукции выяснилось, что основными их проблемамы являются следующие: отсуствие мест хранения (47\%), трудности в получении кредита (27\%), высокие цены машин, техники и технологий (21 $\%)$, недостаточность информации о рынке (5\%) (Рисунок-1). 


\begin{tabular}{l|lrl|l|ll} 
& ISRA (India) & $=\mathbf{1 . 3 4 4}$ & SIS (USA) & $=\mathbf{0 . 9 1 2}$ & ICV (Poland) & $=\mathbf{6 . 6 3 0}$ \\
Impact Factor: & ISI (Dubai, UAE) $=\mathbf{0 . 8 2 9}$ & PUHU (Russia) $=\mathbf{0 . 2 0 7}$ & PIF (India) & $=\mathbf{1 . 9 4 0}$ \\
& GIF (Australia) & $\mathbf{0 . 5 6 4}$ & ESJI (KZ) & $=\mathbf{3 . 8 6 0}$ & IBI (India) & $\mathbf{4 . 2 6 0}$
\end{tabular}

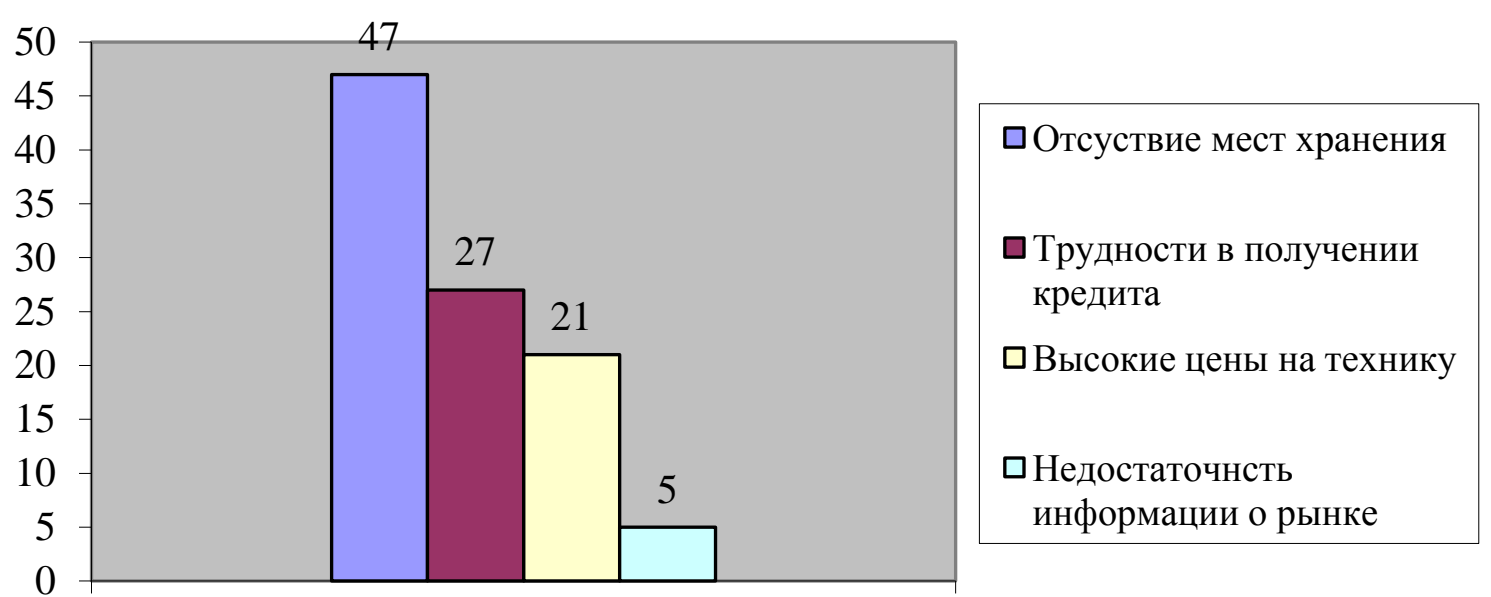

\section{Рисунок 1 - Организационные проблемы в фермерских хозяйств, специализированных в плодоводстве-овощеводстве, процент \\ Источник: Разработаны авторам на основе данных опроса}

В настоящее время имеющиеся в области хранилища подвали, склады с холодильниками имеют мощность в пределах 50 тыс. тонн. Этого не хватить даже на 10 процентов вырашенной продукции в области. Поэтому считаем целесообразным совершенствование деятельности агрофирм.

Состояние обеспеченности фермерских хозяйств области, специализированных плодоводстве-овощеводстве новой техникой тоже неудовлетворительно. Потому что в этой сфере недостаточно их внутренних возможностей. Доля хозяйств, частично обеспеченных новой техникой составляет - 40\%, польностью обеспеченных - 23 $\%$, необеспеченных - 20\%, использующих на основе аренды - 17\%. Данные фермерские хозйства или получили много кредитных ресурсов или вообще не получили кредитов. Основная часть респондентов $(35 \%)$ не получили кредитные ресурсы, получили в размере 5-10 млн. сумов (34\%), до 1-5 млн. сумов (23\%) а также более 10 млн. сум (8\%).

Но среди фермерских хозяйств, специализированных плодоводстве-овощеводстве основное место занимают (47\%) фермерские хозяйства, считающие достаточным возможности собственного капитала. Считающие их дальнейшее увеличение достаточным составляет - $22 \%$ из всех респондентов, считающие недостаточным - $18 \%$, частично достатчным $13 \%$ из всех опрошенных.

Основными потребителями вырашенных фермерскими хозяйствами продукции являются заготовительные конторы (35\%), население $(33 \%)$, предприятия, организации и другие хозяйства $(24 \%)$ и государство $(8 \%)$.

При исследовании проблем, создающих баръер для деятельности фермерских хозяйств
Ферганской области, специализированных плодоводстве-овощеводстве и обеспечение стабильного роста в них вырашивания продукции выявлены следующие факторы: развитие рыночной инфрастуктуры на низком уровне (43\%), не выполнение договорных обязательств (25\%), админстративные и бюрократические баръеры (17\%), низкий уровень управленческих и маркетинговых исследований (15\%).

Также в опросе приведены мнения, по необходимости создания реальных, свободных условий и возможностей при вырашивании и реализации продукции в фермерских хозяйствах, специализированных плодоводстве-овощеводстве (37\% респондентов), по упрощению условий для поставки продукции на внешний рынок (35\%), по вырашиванию продукции в соответствии по имеющимся спросу и предложению на внешнем и внутреннем рынках (18\%) и по созданию микроэкономического климата для фермерских хозйств (инфляция, цена, налоги, кредит, государственная поддержка и стимулирование) (10\% респондентов).

По результатам исследований можно наблюдать необходимости производства продукции (оказание услуг) путем заключения прямых договоров с покупателями по повышению экспортного потенциала в деятеьности фермерских хозяйств, специализированных плодоводстве-овощеводстве и в соответствии спросу и предложению (51\%), изучения зарубежного опыта (22\%), изучения рынков стран СНГ в целях поставки качественной продукции (услуг) (18\%) и далнейшего улучшения качества продукции (9\%). В настоящее время состояние поставки продукции, вырашенной на фермерских хозяйствах такова: до $30-60$ процентов 
выращенной продукции (44\%), до 10 процентов (38), от 10 до 30 процентов (12\%), более 60 процентов (6\%).

Как видно из вышесказанных, в области имеются большие возможности повышения экспортного потенциала в деятельности фермерских хозяйств. Для этого считаем целесообразным создание достаточных условий.

Для этого необходимо обеспечить их достаточной статистической информцией. Потому что при опросе респонденты отметили недостаточность информации (31\%), затруднялись в ответе $(24 \%)$, имеется достаточная инфрмация (23\%), при получении информации используют интернет (22\%) (рисунок-2). По нашему мнению, считаем необходимым создание совместно с управлением статистистики области, Торгово-промышленной палатой, ассоциацией фермерских хозяйств “Информационный уголок”, сайтов интернета для получения необходимой инфрмации. Это дает им возможности получения инофрмации о созданных возможностях по внешней деятельности, составления контрактов, льготам и другие.

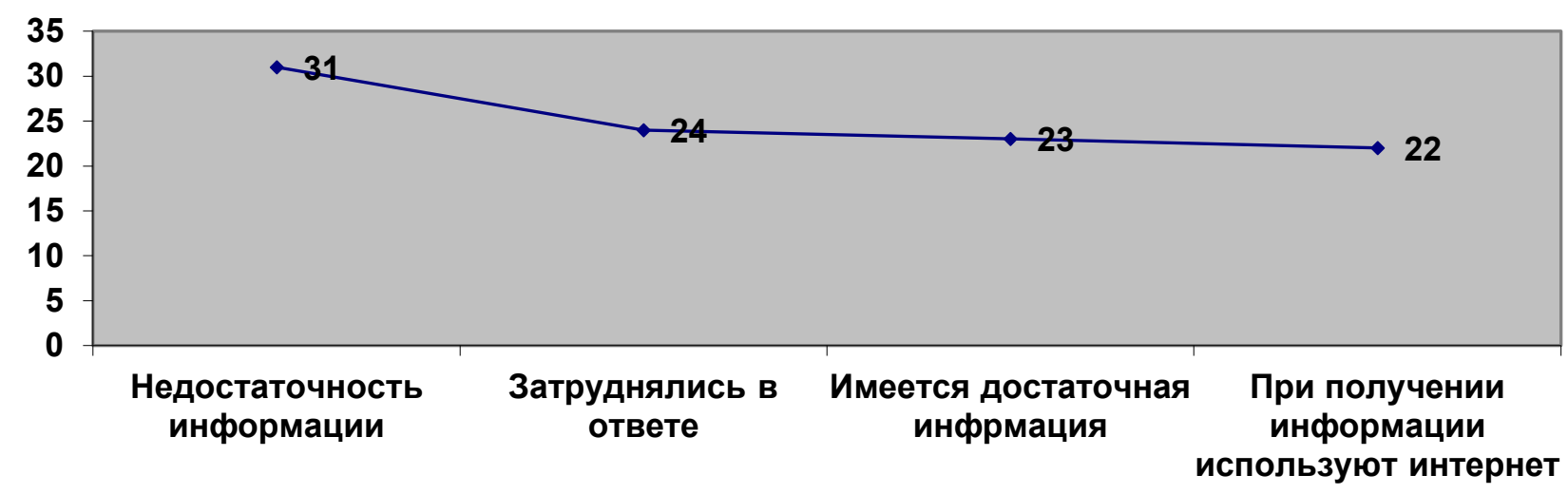

\footnotetext{
Рисунок 2 - Наличие информационной базы в фермерских хозяйств, специализированных в плодоводстве-овощеводстве, процент

Источник: Разработаны авторам на основе данных опроса
}

В данных исследования указаны, что фермерские хозяйства, специализированные в плодоводстве-овощеводстве предоставляют имеющиеся у них данные статистическим органам (54\%), фермерским ассоциациям (21\%), всем требующим организациям (14\%), финансовым органам (11\%).

Также выявлено что, фермерские хозяйства, специализированных плодоводстве-овощеводстве в своей деятельности при определении урожая следующего года опираются на многолетный опыть $(57 \%)$, на требованность продукции в этом году (25\%), ежегодно одинаковую продукцию $(11 \%)$ а также затрудняются в ответе $(7 \%)$.

Таким образом, на основе полученных данных в результате социологических исследований можно образовать базу данных, отражающих социально-экономические отношения в фермерских хозяйствах, они могуть быть полезны обеспечении стабильности фермерских хозяйств, специализированных плодоводстве-овощеводстве на уровни области.

\section{Выводы и предложения}

Исходя из накопленных в результате вышеизложенных исследований, предлагаем следующие для дальнейшего развития и стимулирования деятельности фермерских хозяйств, специализированных плодоводствеовощеводстве Ферганской области:

- пересмотреть предоставление фермерским хозяйствам, специализированным плодоводстве-овощеводстве необходимой финансовой помощи (лизинг, льготное кредитование) для обеспечения их основными средствами;

- создание новых объектов хранения продукции агрофирмами на основе иностранных кредитных линий;

- налаживание выделения отдельных льготных кредитных линий в коммерческих банках для представителей данной сферы.

Считаем необходимым обращение особого внимания на следующие аспекты предлагаемых проектов при выделении кредитов коммерческими банками области фермерским 
хозяйствам, специализированных плодоводствеовощеводстве и всяческую поддержку их:

1. Проекты направленные на развитие предпринимательства в сельской местности, а также, дальнейшее повышение жизненного уровня населения и на этой основе создание новых рабочих мест;

2. Стимулировать проекты направленные на сельское хозяйство, в том числе, на переработку проукции плодоводства-овощеводства;

3. Проекты направленные на производство продукции на внутренний и внешный (экспорт);

4. Проекты, основанные на минитехнолгиях, a также, направленные на модернизацию имеющихся в отрасли плодоводстваовощеводства устаревших средств производства:

- совместно с торгово-промышленной палатой области, ассоциацией фермерских хозяйств и другими заинтересованными организациями организовать выставки по минитехнологиям, формирование необходимой базы данных по приобретению;

- в целях дальнейшего увеличения начального капитала оказание услуг коммерческих банков;

- формирование базы данных о внешнем и внутреннем рынке, перерабатывающих предприятиях, потреблении населения данной продукции, их ценах, объемах покупки и других.

5. По нашему мнению предлагается включать в круг вопросов, решаемых системой статистических информаций следующие:

1) Определение содержательной части статистической информации, то есть определить значимость необходимой информации;
2) Оказание помощи при выборе информации, необходимой для разработки управленческих решений по отрасли;

3) Определение срочности статистической информации, его достоверности и самого выгодного соотношения между расходами получения необходимой информации;

4) Разработка регламента порядка поучения статистической информации;

5) Определение способов обработки, их анализа, хранения, сбора, контроля и распространения статистической информации.

6. Такие вопросы, как широкое применение в изучении требований рынка плодово-овощной продукции в области способов частичного статистического наблюдения (анкетный опрос, монографическое наблюдение, выборочное наблюдение), предоставление производителям необходимой информации о рынке и потребителей, формирование у специалистах статистиках и у руководителей рыночных навыков. Целесообразным является налаживание выборочного наблюдения в фермерских хозяйствах, специализированных плодоводствеовощеводстве, но в этой области имеются проблемы, которые ждут своего решения и мероприятия, осуществление котрых является обязательным. В том числе, выращенная фермерскими хозяйствами продукция в большинстве случаев недоходит до покупателей или реализуется по низким ценам. Для решения данной проблемы требуется системное осуществление анализа в статистических способах, развития систем хранения и заготовке, а также распределения и реализации.

\section{References:}

1. Agarkova L.V. (2007) Formirovanie mekhanizma ustoychivogo razvitiya plodoovoshchnogo podkompleksa: teoriya i praktika. - Stavropol': Stavrolit, 2007. - p.168.

2. Baranov I.A. (2003) Sovershenstvovanie kommercheskoy raboty torgovykh i zagotovitel'nykh organizatsiy potrebitel'skoy kooperatsii. Avtoref. diss. d-ra ekon. nauk. M.: RGB, 2003. - p.39.

3. Popov N.A. (2005) Ekonomika sel'skogo khozyaystva. -M.: Delo i Servis, 2005. - p.56.

4. Afanas'eva A.V. (2008) Statisticheskaya otsenka dinamiki proizvodstva sel'skokhozyaystvennoy produktsii $\mathrm{v}$ sisteme gosudarstvennogo regulirovaniya prodovol'stvennogo rynka. Avtoref. Diss. na sois.kand. ekon. nauk. - Samara.2008. -p.26.

5. Solomakhin M.A. (2005) Osnovnye napravleniya sovershenstvovaniya sistemy vedeniya sadovodstva $\mathrm{v}$ usloviyakh razvitiya agropromyshlennoy integratsii//Organizatsionno-ekonomicheskie problemy stabilizatsii i razvitiya agrarnogo sektora ekonomiki. Tom 1: Materialy nauchnoprakticheskoy konferentsii 9-10 noyabrya 2005 g. Michurinsk: Izd-vo FGOU VPO MichGAU, 2005. - Tom 1. -p.153-159.

6. Grekov N.I. (2005) Osnovnye napravleniya i faktory intensifikatsii sadovodstva.// Organizatsionno-ekonomicheskie problemy stabilizatsii i razvitiya agrarnogo sektora 


\begin{tabular}{l|lrl|l|ll} 
& ISRA (India) & $=\mathbf{1 . 3 4 4}$ & SIS (USA) & $=\mathbf{0 . 9 1 2}$ & ICV (Poland) & $=\mathbf{6 . 6 3 0}$ \\
Impact Factor: & ISI (Dubai, UAE) $=\mathbf{0 . 8 2 9}$ & PUHL (Russia) $=\mathbf{0 . 2 0 7}$ & PIF (India) & $=\mathbf{1 . 9 4 0}$ \\
& GIF (Australia) & $\mathbf{0 . 5 6 4}$ & ESJI (KZ) & $=3.860$ & IBI (India) & $=\mathbf{4 . 2 6 0}$ \\
& JIF & $\mathbf{1 . 5 0 0}$ & SJIF (Morocco) & $=\mathbf{2 . 0 3 1}$ & & \\
\hline
\end{tabular}

ekonomiki. Tom 1: Materialy nauchnoprakticheskoy konferentsii 9-10 noyabrya 2005 g. Michurinsk: Izd-vo FGOU VPO MichGAU, 2005. - Tom 1. -p.164-166.

7. Asadulina N.R. (2006) Mekhanizm regulirovaniya effektivnosti plodoovoshchnogo kompleksa Respubliki Uzbekistan na osnove logisticheskogo podkhoda. Diss.na sois. uchen. step. kand. ekon. nauk. - T.:-2006.-p.158.

8. Burhonov A.X. (2000) Turli mulkchilik shaklidagi qishloq xo'jalik korxonalarida ishlab chiqarish iqtisodiy samaradorligini oshirish. Iqt. fan. nom. ilm. dar. olish uchun yozilgan dis.T.: O`zBIITI, 2000. - p.117.

9. Mirzayev M.M. (2006) Mevali daraxtlardan yuqori hosil yetishtirish. - T.- 2006. R.R.Shreder ITI-p.100.

10. Murodov CH. (2001) O‘zbekiston iqtisodiyotini erkinlashtirish sharoitida bozor infratuzilmasini rivojlantirish. Iqt.fan. dokt. ilm. dar. olish uchun yozilgan dis. avtoref. - T.: - 2001. - p.46.

11. Nazarova F. (2001) Iqtisodiyotni erkinlashtirish sharoitida O`zbekiston agrar sektorini rivojlantirish istiqbollari. Iqt. fan. dok. ilm. dar. olish uchun yozilgan dis.-T.:-2001.-p.290.

12. Umurzakov U.P. (2003) Puti povisheniya effektivnosti ispolzovaniya resursnogo potentsiala agrarnogo sektora ekonomiki (na materialakh Respubliki Uzbekistan). Avtoref. diss. na sois. uchen. step. d-ra ekon. nauk. T.:-2003. - p.43.

13. Xushvaqtova X.S. (2005) Bozor sharoitida meva-sabzavot kichik majmuasida agrosanoat integratsiyasini rivojlantirishning tashkiliyiqtisodiy muammolari. Iqt.fan. nom.ilm.dar. olish uchun yozilgan dis. avtoref.- T.: -2005. p. 25 .

14. Ergashev E.I. (2009) Iqtisodiyotni erkinlashtirish sharoitida bog'dorchilik va uzumchilik tarmog'ini rivojlantirishning asosiy yo "nalishlari. Iqt. fan. nom. ilm. dar. olish uchun yozilgan diss. avtoref.- T.:-2009.-p.22.

15. Muxitdinova U.S. (2010) Iqtisodiyotni modernizatsiyalash sharoitida mevasabzavotchilik mahsulotlari bozorini rivojlantirish yo'nalishlari. Iqt.fan.dok.ilm. dar.olish uchun yozilgan dis.avtoref.-T.:2010.p. 36 .

16. Ochilov S., Ergasheva S. (2008) Qishloq va suv xo'jaligi statistikasi. O‘quv qo'llanma. -T.: 2008. -p.192.

17. Rakhmatov M. (1989) Razvitie plodoovoshchnogo podkompleksa V Ferganskoy oblasti. Avtoref. diss.na sois. kan. ekon. nauk.-T.: 1989.-p.24. 